\title{
A MicrocidadeTapira A Macroempresa VALEP e o Planejamento Tecnocrático Brasileiro*
}

\section{Resumo}

Este trabalho tem como objeto geral o processo de planejamento urbano como atividade política, visto em suas manifestações concretas num município do sudoeste de Minas Gerais, denominado Tapira, com cerca de 2.000 habitantes, no período que se inicia em 1975 e vem até os dias atuais.

A pesquisa busca não só demonstrar a natureza política do planejamento, como descobrir alguns modos pelos quais ela se manifesta concretamente, dando realce às reações populares ao que foi decidido e desencadeado pela cúpula.

$\mathrm{E}$ ao desvendar os problemas sociais/econômicos/políticos/espaciais ocorridos em Tapira poderei conhecer melhor o processo histórico atual brasileiro.

This work has a general aim - the urban process planning as a political activity, seen in its concrete manifestations in a small town on the southwest of Minas Gerais. It is called Tapira and it has had about 2.000 inhabitants, from 1975 to our days.

The research aims not only to demonstrate the political planning, but also to discover some ways by which it shows up concretely, emphasizing the popular reactions to what has been decided and put into practice by government.

In disclosing the socio-political, economical and spacial problems ocurred at Tapira I will be able to known much better the up-to-date historic process in Brazil. 


\section{Introdução}

Esta pesquisa tem como objeto geral o processo de planejamento urbano como atividade política, visto em suas manifestaçōes concretas num município de Minas Gerais, Tapira, com cerca de 2.000 habitantes, no período que se inicia em 1975 e vem até os dias atuais.

Ela parte do pressuposto de que, estando mergulhado em relaçōes de poder que o antecedem e o transcendem enquanto processo histórico, o planejamento tende a reforçar ou redefinir privilégios econômicos e políticos preexistentes, por impotência, inércia ou conivência de seus técnicos ante essas forças.

No entanto, ela aceita também de antemão que a história se faz através de contradições. Em decorrência, o trabalho tem por objetivo verificar a hipótese de que, ainda que o planejamneto urbano resulte no privilegiamento de determinados grupos sociais, e ainda que não distribua benefícios a todos os segmentos da sociedade envolvida, pode mobilizar apoio de um conglomerado diferenciado de camadas sociais, conseguindo aprovação de parcela significativa, senão da maioria, da população atingida.

Portanto, este trabalho busca não só demonstrar a natureza política do planejamento, como descobrir alguns modos pelos quais ela se manifesta concretamente. Existe nele a preocupação em mostrar como essas relações de poder afetam etapas decisórias e o próprio sentido do planejamento. Ele quer identificar os agentes direta ou indiretamente envolvidos, quais são seus interesses em jogo, e de que mecanismos se valem para influir no processo.

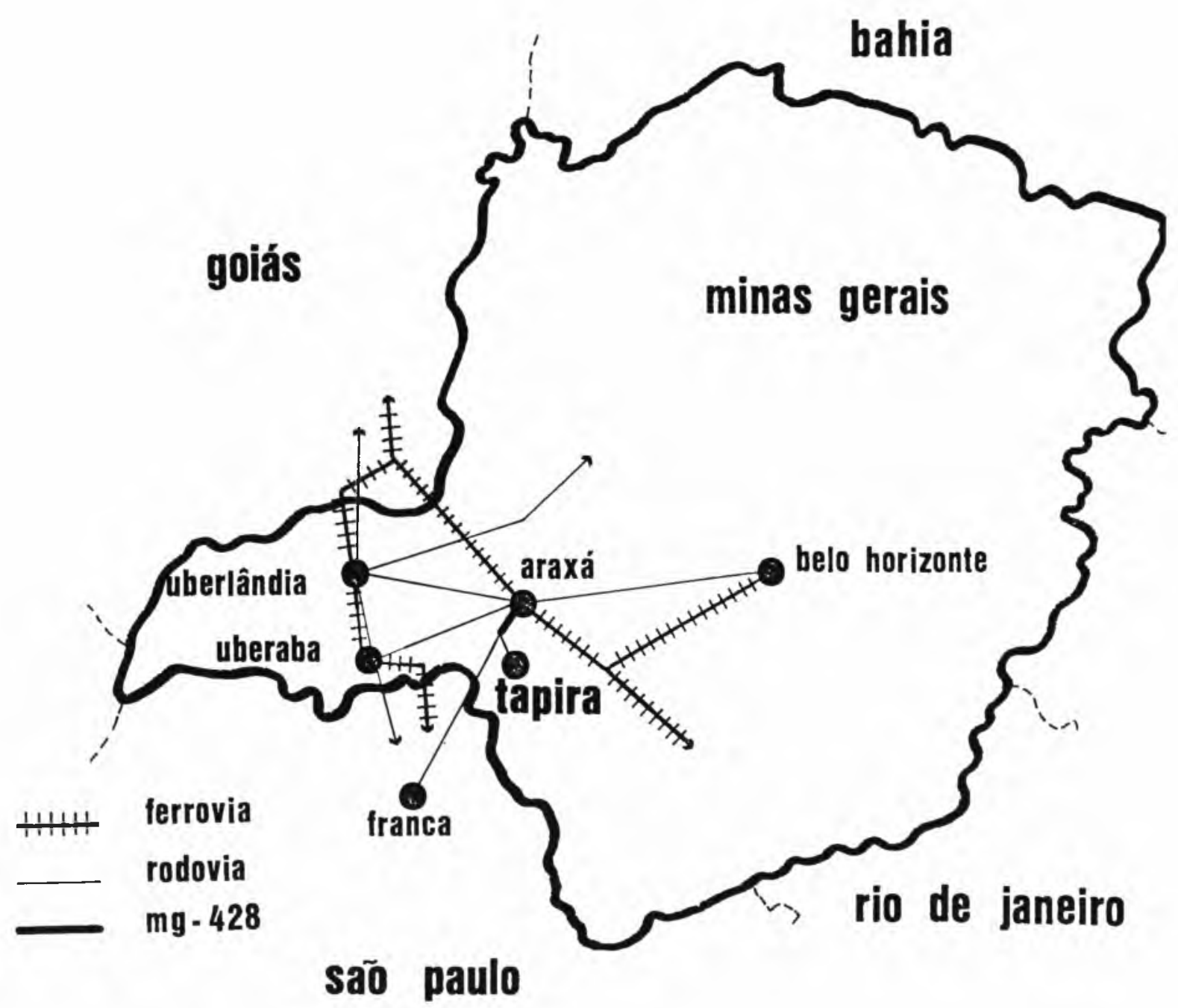


Importa-se em saber as reações populares ao que foi decidido e desencadeado pela cúpula.

Para averiguar essas colocações mais gerais, o trabalho elege o microcosmos de relaçōes sócioespaciais representado por um município diminuto, em momento de redefinição de relações de forças por sua absorção na linha de frente de investimentos capitalistas.

Tapira é uma cidadezinha fundada no início do século 20 , com economia basicamente centrada na agropecuária até 1975 , quando ali se instala a Cia. Vale do Rio Doce. Até entāo o assentamento urbano era espontâneo, resultando da forma de apropriação do solo e de facilidades geográficas. Com o aumento populacional ocorrido depois da implantação da mineradora a mancha urbana ampliou-se.

O crescimento da cidade deu-se primordialmente em função da mineradora VALEP, subsidiária da Cia. Vale do Rio Doce que, ao trazer expectativa e oportunidades de empregos, não só atraiu imigrantes, como fez aumentar a renda de alguns moradores, que começaram a exigir do poder local novos equipamentos urbanos.

As necessidades urbanísticas desse grande capital aliadas às reivindicações sociais crescentes aconteceram num momento propício para que um plano urbano fosse proposto porque tornava-se exigência do governo federal que os municípios com mais de vinte mil habitantes tivessem o seu para receber verbas. Por solicitação do governo local ao governo do estado mineiro, apesar de

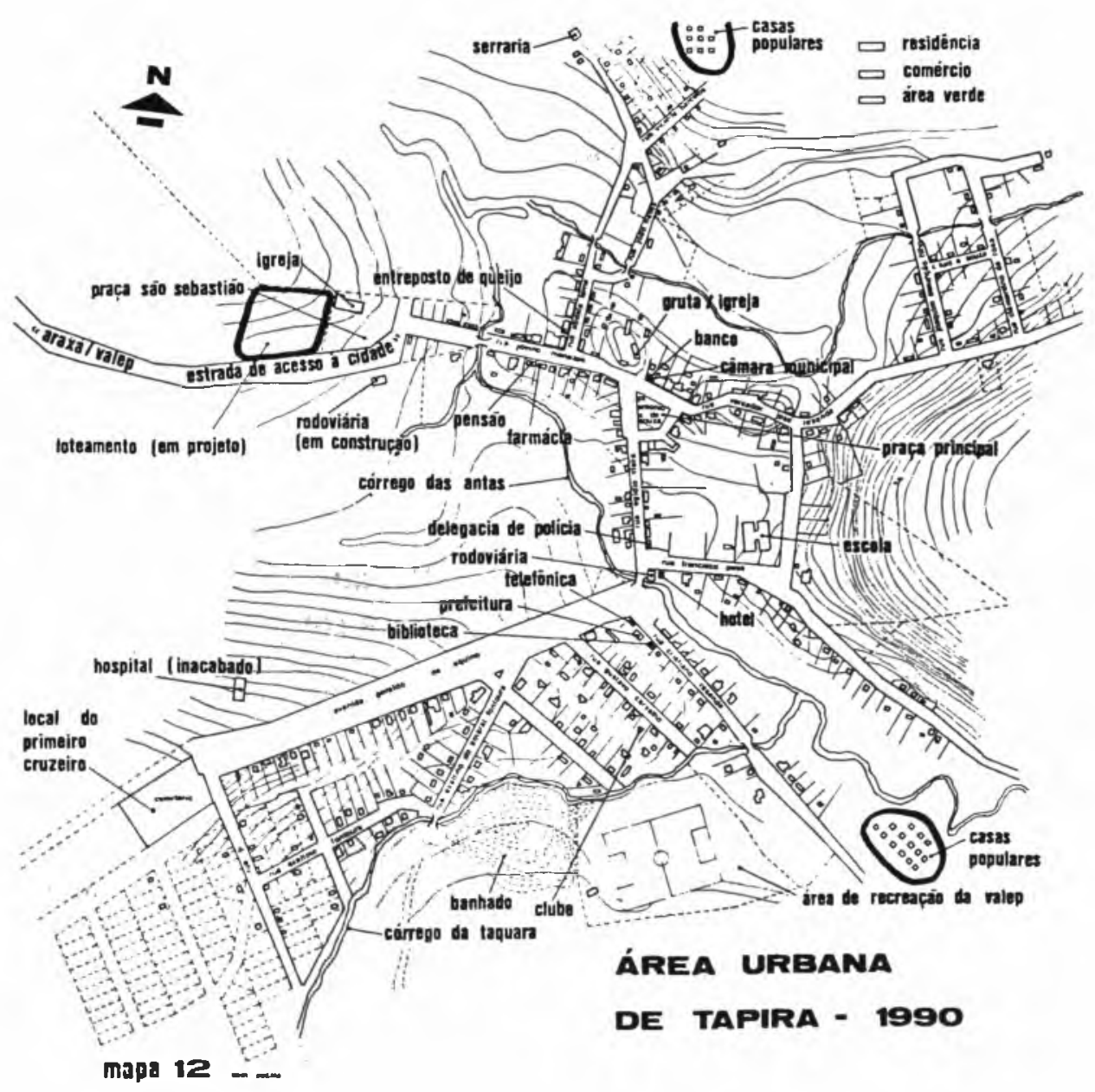


dez vezes menor que esse padrão mínimo, o município de Tapira foi presenteado com um plano diretor, feito pela Fundação João Pinheiro, de Belo Horizonte, em 1978.

Hoje, década e meia após a implantação da CVDR e do plano ser legalmente aprovado e reconhecido pela prefeitura, são perceptíveis novas relações sociais, econômicas e políticas, com reflexos no espaço urbano. O plano, suas condições de aplicação, seus efeitos espaciais e sociais constituem meu objeto específico de estudo.

Em meados de 1984, visitei pela primeira vez a cidadezinha de Tapira e logo identifiquei elementos e relações interessantes para meu projeto de pesquisa. Eis alguns fatos que chamaram minha atenção.

1. As dimensões de sua área urbana: o lugarzinho era tão pequeno que mais parecia parte de um bairro pouco povoado de uma cidade do interior do país.

2. As relações sociais que lá se davam: a maioria da população parecia fazer parte de uma grande família, ou seja, era aparente uma organização social do tipo comunitário.

3. A "confusão" que os ocupantes dos cargos públicos faziam entre os interesses privados, ou seja, uma concepção patrimonialista do Estado por parte dos políticos e administradores públicos.

4. A falta de interesse da população por assuntos políticos.

5. As obras urbanas que aconteciam em algumas ruas da cidade e a repentina ou "inesperada" valorização dos terrenos circunvizinhos.

6. A falta de comércio e indústrias no município.

7 A precariedade dos serviços públicos.

8. E, o que mais me impressionou, a existência de um plano diretor para regular e ordenar o uso do solo urbano.

Este último item aguçou meu interesse em conhecer com mais profundidade 0 local e estudar qual a razão desse fenômeno e sua relação aos outros apontados.

Foi, portanto, a partir do conhecimento da existência do plano diretor de Tapira que comecei a levantar uma série de questões que conduziriam posteriormente as minhas investigações.

Por que um núcleo tão pequeno possuía um plano diretor?

Quem teve (ou tinha) interesse em sua existência?

Houve apenas coincidência entre a entrada da CVRD no município e a aprovação do plano diretor pela prefeitura ou houve relação causal entre os dois fatos?

Por que não existia nenhum exemplar do plano diretor na prefeitura local?

Alguém se favorecia com o "desaparecimento" do plano?

Talvez uma questão de base pudesse resumir minha inquietação: com a implantação da CVRD naquelas terras meio isoladas, o que se modificou na estrutura sócioeconômica do município e o que isso teve a ver com o planejamento urbano?

Acredito que a metodologia e as técincas que adotei para abordar o objeto foram de extrema importância para que eu pudesse analisar com clareza aquela 
cidadezinha e por conseqüência o tema central da pesquisa. Por este motivo optei por descrever, neste artigo, justamente esta parte de minha experiência de pesquisa, da qual resultou uma mudança da minha visão sobre planejamento urbano no Brasil.

\section{Metodologia e Técnicas de Pesquisa Adotadas}

As minhas primeiras visitas à cidade de Tapira coincidiram com a implantação recente do Vale do Rio Doce naquelas terras. Não poderia, portanto, ter me espantado com a falta de colaboração da população e muito menos com a associação que todos passaram a fazer de minha pessoa com a companhia.

A princípio pensei em desenvolver a pesquisa junto à população através de questionário/respostas diretas. Por ser uma cidade muito pequena, com cerca de 2.000 habitantes, acreditei poder fazer um levantamento com a totalidade dos habitantes. Porém, ao freqüentar mais constantemente o lugar percebi que isso seria praticamente impossível. Apesar de bastante amáveis, os habitantes de Tapira, estavam extremamente desconfiados de qualquer "forasteiro" que deles se aproximasse ficando is to claro a medida que eu, nos primeiros testes que fiz com o questionário, não obtive resposta para a maioria das perguntas. Aquilo me intrigava até que um dos entrevistados perguntou-me qual minha função na CVRD. Como eu não havia entendido antes? A companhia para eles vinha associada a idéia de destruição da cidade. E eu, uma desconhecida, fazendo tantas perguntas, só poderia estar ali para levantar dados sobre os imóveis urbanos e avaliá-los a fim de que a companhia pudesse posteriormente aproximarse de seus proprietários com uma oferta para comprá-los. Segundo a população, a intenção dela era remover a cidade para poder explorar todo aquele subsolo. Pensando assim ficava lógico a atitude de todos. Quanto mais eles pudessem sonegar informações à pesquisadora, melhor para a cidade e para cada um individualmente. Além disso, eu precisava entender que aquela população não estava acostumada à pesquisa. Hoje, todas as cidades brasileiras de porte médio ou grande convivem freqüentemente com pesquisadores. Ninguém mais se surpreende com suas presenças nas esquinas e muito menos com suas perguntas. Mas em Tapira a realidade era bastante diferente.

Só após ter entendido tudo isto é que pude começar meu trabalho junto à população.

O problema que encontrei para me aproximar da população também aconteceu quando precisei obter dados junto às autoridades. Nenhuma pessoa que ocupava cargos dirigentes na sociedade local se prontificava a responder as perguntas que thes eram formuladas, o que me levou a repensar sobre o método previamente escolhido.

Quanto aos cadastros da prefeitura e do IBGE foram de pouquíssima utilidade, pois estavam bastante desatualizados e com poucos dados significativos para a pesquisa.

O registro de imóveis além de estar desatualizado não era feito na própria cidade, o que dificultava ainda mais sua consulta. Isto se agravava à medida que os documentos (com exceção dos documentos do IBGE) eram obtidos através de pessoas que favoreciam seu emprés timo, levando a uma situação de dependência pesquisadora/pessoal administrativo da municipalidade. 
O plano diretor não pôde ser consultado em 1985, quando colhi os primeiros dados, pois não havia um único exemplar na prefeitura, não sendo encontrado durante o período em que lá encontrava-me.

A aprovação de projetos e a regularização de loteamentos era feita, em 1985, por um engenheiro que vinha do município mais próximo. Araxá, uma vez por semana e dizia conhecer de cor o plano diretor. Enquanto freqüentei a cidade nunca por lá ele esteve e mesmo tendo sido procurado, em Araxá, recusou-se a atender-me. Somente em outubro de 1990 pude obter e analisar o plano. $\mathrm{Na}$ Fundação João Pinheiro só obtive dados através de sua revista assim mesmo nada específico sobre o município, e os técnicos que contactei, quando de minha ida a Belo Horizonte, alegaram ignorar o plano.

Os poucos dados que obtive da superintendência da Cia. Vale do Rio Doce, em Belo Horizonte, confirmaram informações dadas por outras pessoas não ligadas à empresa, mas não cobriram todas as áreas de interesse para a pesquisa.

Portanto, a pesquisa tornou-se mais difícil do que o esperado, obrigando-me a tomar outras medidas.

É claro que nem todas as lacunas foram preenchidas, mas o material obtido foi suficiente para o estudo que me propus.

Diante das dificuldades encontradas logo ao iniciar a pesquisa de campo, percebi que, talvez, esta etapa do trabalho devesse seguir fundamentalmente os procedimentos metodológicos adotados em levantamentos antropológicos, como nos estudos de comunidades.

Então, a partir de meados de 1984 até dezembro de 1985, passei a freqüentar a cidade de Tapira todos os finais de semana.

Com is to fui conhecendo cada um dos moradores e seu papel naquela sociedade. Aos poucos obtive a confiança da maioria. Como não poderia utilizar os clássicos questionários, conforme já expus, adotei o diário como forma de registrar as informaçōes obtidas durante o dia em conversas informais. Nenhum detalhe poderia ser desprezado a princípio e, portanto, deveria ser adotado.

Neste primeiro fichamento procurei apenas transcrever o que ouvia, sem utilizar nenhum juízo de valor ou análise para os dados. Cada tipo de informação era passado para uma ficha, sendo que cada uma delas recebia um número e uma letra. Era esta letra que identificava o tipo de fonte do dado. Por exemplo: letra A para dados obtidos nas conversas com moradores; B para dados sobre fotos; C para documentação oficial; D para mapas... Numa outra ficha constava o número e letra da primeira ficha. Nela era registrada a data, fonte e o local da obtenção dos dados. Isto facilitava meu trabalho, pois podia procurar qualquer informação que me interessava a qualquer momento e com bastante rapidez.

Após exaustivo fichamento de tudo o que a população me oferecia, iniciei a seleção do que para o trabalho era relevante.

Comecei contando os dados obtidos a fim de verificar a freqüência com que apareciam, e o que poderia conduzir-me a fatos importantes. Mas só com o cruzamento de informações é que acreditei poder considerá-los confirmados e verídicos.

Não só os fatos tornavam-se emergentes mas as pessoas que naquela sociedade exerciam algum tipo de ascendência. Para a pesquisa isso foi de fundamental importância. Ao identificar os personagens-chaves passei num segundo momento a me ater às informações dessas pessoas. A técnica foi a mesma adotada na primeira fase, o diário e o posterior fichamento de tudo. 
Ao mesmo tempo eu precisava completar a pesquisa com outros dados, pois só aqueles fornecidos pela população eram insuficientes. Órgãos oficiais (IBGE, prefeitura municipal...) foram visitados e seus arquivos vasculhados.

Os dados oficiais e mapas encontrados na prefeitura de Tapira tiveram que ser transcritos a punho, pois a cidade, em 1985, nāo possuía nenhuma máquina copiadora, o que não só dificultava o trabalho como o tornava mais moroso. Isto para os dias de hoje, quando a tecnologia está a nossa inteira disposiçāo, é inadmissível.

As demais informaçōes que eu precisava obter estavam na Cia. Vale do Rio Doce e Fundação João Pinheiro, ambas com diretoria e equipe técnica localizadas em Belo Horizonte. Por este motivo, em julho de 1985, desloquei-me para a capital mineira, imaginando lá encontrar respostas para muitas lacunas existentes até então. Para chegar às pessoas que realmente pudessem trazer-me contribuições relevantes utilizei-me, novamente, de "amizades influentes" que facilitaram meu acesso à Cia. Vale e à fundação.

Nos dois locais utilizei a técnica de entrevista com perguntas/respostas diretas, que acreditei ser a mais adequada já que ambos estão familiarizados com ela. Mesmo não tendo obtido os resultados esperados, sei que o insucesso não se deveu à técnica escolhida, mas aos fatos de que uma (a fundação) não possuía as informações e a outra (a companhia) não as forneceu por motivos estratégicos, ou seja, sigilo empresarial.

O outro problema que eu tive dizia respeito à amostragem e sua representatividade.

Qual seria a amostra adequada para a partir dela fazer generalizações ou conclusões? A resposta veio com a leitura do livro de Francis $\mathrm{Hsu}(\mathrm{O}$ estudo das civilizaçōes letradas) pois este mostra que no campo antropológico há falta de critério a esse respeito. "Faltando tal critério aqueles que empregamos atualmente para avaliar o valor de um estudo de campo é primordialmente qualitativo" e "a decisão de quantos informantes são necessários é basicamente uma decisão estrutural" (HSU, Francis. 1974. p. 47/66).

Além disto, cada informante deve ser aceito pelo pesquisador como uma fonte digna de crédito.

Segundo o mesmo autor, os enormes obstáculos "apresentados pela vastidāo e complexidade de sociedades letradas são compensados pela maior disponibilidade de materiais publicados sobre o tema e pela existência das pessoas do lugar" (idem, p. 47). Partindo deste princípio procurei ouvir o maior número possível de pessoas, tomando sempre seus depoimentos como verídicos e dignos de crédito. Porém, para considerá-los importantes para minha pesquisa e não incorrer em graves erros, tomei como regra só aceitar aquelas colocações que por mais de uma pessoa fossem feitas.

E o mais importante é que eu jamais poderia tomar aquele lugar como uma sociedade completamente isolada do restante do espaço social, político, econômico e cultural brasileiro.

A pesquisa bibliográfica sobre a história brasileira tornou-se peça fundamental neste processo. Textos clássicos da literatura econômica e política, trabalhos específicos sobre planejamento urbano nos decênios estudados davam apoio teórico necessário para o entendimento da sociedade local. Por este motivo, tudo o que era levantado na pesquisa de campo era incluído dentro de um contexto maior, a fim de que não só se encontrassem as peculiaridades daquele espaço, mas principalmente elementos que pudessem levar às generalizações 
válidas para a sociedade brasileira, que em última instância é o objeto da pesquisa.

\section{Considerações Finais}

Quando conheci Tapira, em 1984, imaginei estar em outro tempo. Aquele lugar precisava ser preservado a qualquer custo, pensava eu. Enquanto freqüentei com mais assiduidade Tapira, situei-me valorativamente não como pesquisadora, mas como moradora do lugar. Por is to minha posição não podia ser diferente da de seus habitantes: eu tinha repulsa pela companhia e pelo planejamento proposto. A empresa, recentemente instalada, vinha para desestruturar 0 "pequeno paraíso" afirmavam seus moradores. Com o passar do tempo e ao analisar mais fria e detidamente os dados coletados fui percebendo que aquilo que eu via romanticamente não existia de fato. Os diferentes grupos sociais "brigavam" pelo poder. Os pequenos proprietários aliavam-se aos grandes quando queriam preservar privilégios mesmo que depois fossem ignorados ou "atraiçoados" por eles. A vida aparentemente tranqüila era ilusão: na realidade a sociedade local estava impossibilitada de se aproximar do "progresso" por pobreza e não por opção. Tão logo the "ofereceram" uma imagem de televisão todos vibraram. Aí eu percebi que aquele grupo social, tão distante espacialmente de São Paulo, tinha provavelmente, os mesmos desejos que os moradores da grande metrópole. Então por que privá-los das facilidades de que a sociedade contemporânea usufrui?

A história mostrou-me que Tapira um dia fora incorporada de nova forma, muita estreita, pelo "mundo capitalista" Se era assim, o que havia de se discutir não era o regresso ao passado e sim as mais justas condições sociais de se avançar nesse futuro, ao mesmo tempo tão inelutável e tão aspirado popularmente.

Revisei meus conceitos, ponderei as justificativas para tal fato e acabei "descobrindo" que o planejamento era o mal menor. Num país comadministração planejada pode ser mais fácil para pequenas cidadezinhas, como Tapira, sobreviverem dignamente. E um bom plano municipal ao qual seja dada continuidade, instaurando um processo de planejamento no qual se incluam avaliações e revisões periódicas poderia evitar sérios dados à saúde e melhorar - bem-estar da população. Em conseqüência, para garantir e ampliar sua qualidade de vida, os moradores de Tapira têm de assumir a grande empresa estatal hoje, privada eventualmente amanhã - faz parte de seu des tino e deve por isso ser por eles supervisionada de forma preferencialmente planejada.

O planejamento faz parte da racionalidade econômica das empresas. 0 planejamento social pode fazer parte do crescimento democrático e da cidadania, processos em construção no Brasil.

* Resumo da dissertação do mesmo nome, orientada pela Prof Dr Maria Irene Szmrecsányi, e defendida em 1993. 